\title{
In-Depth Learning Layout and Path Optimization of Energy Service Urban Distribution Sites under e-Commerce Environment
}

\author{
Kun Wang ${ }^{1,2}$ and Ki-Hyung Bae (iD) ${ }^{1}$ \\ ${ }^{1}$ Department of Economics, Sejong University, Seoul 05000, Republic of Korea \\ ${ }^{2}$ College of Foreign Language and Tourism, Henan Institute of Economics and Trade, Zhengzhou 450018, China
}

Correspondence should be addressed to Ki-Hyung Bae; x201710729377@stu.ncwu.edu.cn

Received 31 October 2020; Revised 25 January 2021; Accepted 28 January 2021; Published 8 February 2021

Academic Editor: Wei Wang

Copyright (c) 2021 Kun Wang and Ki-Hyung Bae. This is an open access article distributed under the Creative Commons Attribution License, which permits unrestricted use, distribution, and reproduction in any medium, provided the original work is properly cited.

\begin{abstract}
This article uses a research method that combines theoretical research and empirical analysis. It first introduces the relevant theories of energy service city distribution sites in the context of e-commerce and then the types of energy service city distribution sites and the composition of energy service city distribution systems. The network layout of the service city distribution site and the location objectives, principles, and processes of the model is studied to determine the network layout plan of the energy service city distribution system in this paper. This paper fully considers the characteristics of the network operation mode of the energy service city distribution site and establishes an optimization model for the location selection and vehicle routing of the distribution center with the lowest total system cost under the simultaneous delivery service mode; based on the hierarchical solution strategy, a combination of deep learning is designed. Algorithms mainly include two-stage hybrid heuristic algorithm of cluster analysis, maximum coverage and genetic algorithm; simulation analysis is conducted to verify the effectiveness of the model and algorithm by data simulation, finally get the integrated optimization plan of distribution center location and routing, and put forward the operation strategy through the result expansion analysis. This paper studies the planning model based on the network layout planning of the energy service city distribution system under the e-commerce environment, aiming to promote the breakthrough development of urban smart logistics and prove the importance of the energy service city distribution station network layout planning. The purpose and results of the research are to reduce traffic and environmental pressures, achieve joint direct distribution, improve the efficiency of urban logistics and distribution, and solve the problem of the last mile of the city.
\end{abstract}

\section{Introduction}

The rapid development of e-commerce has brought about changes in people's consumption habits, and it has also caused a large amount of urban logistics burden on the per capita road area at a relatively low level. Road's cargo transportation has made the road load more serious. According to statistics, more than $60 \%$ of vehicles on urban roads are used to transport goods [1-4]. In urban transportation and development, freight transportation plays an important role [5]. It can promote the growth of the urban economy and ensure the circulation of goods and the supply of daily goods between cities. At the same time, freight transportation also brings many negative effects to the city, such as transportation congestion, environmental pollution, and other issues [6]. The good operation of freight transportation in the city can significantly promote the development of the city, but if the problems arising from it are not paid attention to and resolved, the chaos in the freight system will also hinder the development of the city [7]. Therefore, to solve the problems of urban traffic congestion, it is important to optimize the freight transportation system in the city [8]. In order to alleviate the pressure of urban transportation, alleviate the contradictions of urban resources, and improve the quality and efficiency of urban logistics, many domestic and foreign scholars have conducted research and exploration on solving urban freight transportation problems and promoting the healthy 
development of urban transportation, looking for a new road suitable for the future development of freight logistics [9].

Related research on the conceptual model of the cabin underground logistics system based on pipeline technology is relatively extensive, mainly focusing on the use of bladders as the means of delivery of cargo, to study the design of transportation vehicles and pipelines [10]. Wiig established the experimental model of electromagnetic cabin pipeline transportation and analyzed the actual operating parameters [11]; Raven analyzed the experience and future development trend of PCP application in Japan [12]; Verrest and Pfeffer analyzed the cabin pipeline transportation in the application situation and development experience of Britain and Europe and made a detailed analysis of the advantages and disadvantages of cabin pipeline transportation [13]. There are also conceptual models of vehicles for underground logistics systems such as CargoCap, which are generally powered by electricity [14]. Part of the underground logistics system is realized by using the perfect urban subway system [15]. It is an underground city freight concept model. It adopts the operation mode of passengers and goods in the same train and different cars and delivers the goods to the terminal through the connection with the ground station [16]. Eckhoff and Wagner proposed using the subway to realize the potential of freight transportation and made practical attempts [17]. Sandulli et al. analyzed the feasibility and problems of urban subway freight transportation and proposed the concept of urban logistics based on subway transportation [18]. Rossi proposed a conceptual model of subway combined underground logistics system [19]. The analysis of various factors of the design is carried out, and the calculation model and route planning are proposed [20].

Domestic LRP research started late, and the main research results have been concentrated in the past ten years. Sookhak et al. first summarized the research situation of foreign LRP optimization problems, proposed modeling and algorithm requirements for the problem, and gave future research directions [21]. Based on the research of foreign scholars, domestic research considers more realistic constraints in combination with different application scenarios and seeks breakthroughs in solving algorithms. The model is closer to reality and the algorithm is more efficient. Kitchin and other companies have designed a response framework for logistics risks' early warning by analyzing the measures taken by domestic and foreign companies for logistics risk early warning and response measures [22]. Wang and others used Stackelberg's countermeasure model to analyze the problem of cooperating and internalizing the risk-averse secondary supply chain and measured how the overall risk aversion coefficient of the supply chain affects its returns and its relative degree of impact [23]. Vu and Hartley analyze the business operation risk of the enterprise's strategic alliance, determine its risk evaluation index, and determine its index weight in conjunction with the F-AHP method, so that the enterprise can make relevant decisions to avoid risks according to its own situation, and its strategic alliance achieves a win-win situation [24].
By identifying and determining the operational risks of energy service city distribution sites in an e-commerce environment, the relevant factors of different operation risks of energy service city distribution sites are added to their game behaviors and the existence of a penalty mechanism for energy service city distribution sites. Next, in-depth analysis of the stable and balanced state of the enterprise members of the energy service city distribution site is carried out. Based on the network structure and operation mode of the energy service city distribution site network, this paper uses operations' research integer programming model and graph theory to abstract LRP into a complex network and abstract the composition objects in the energy service city distribution site network as nodes. The vehicle transportation line is abstracted as an edge, and a problem model is established to study the systematic integration decision of location and distribution under the constraints of time window and capacity. Full-text research is carried out under the idea of overall system optimization.

\section{Energy Service City Distribution Site Model Construction}

\subsection{The Establishment of an Index System for Energy Service} Urban Distribution Sites in an e-Commerce Environment. The evaluation index system is based on the characteristics of the evaluated object and the evaluator's purpose, combined with the actual situation and theoretical experience, to form a certain level of logical structure of the index system [25]. The evaluation index system should organically integrate expert opinions, evaluation purpose, and evaluation methods. The location of the energy service city distribution site center is a crucial step in the network layout of the energy service city distribution system. The main research content of this chapter is to comprehensively evaluate the factors influencing the location of underground logistics system, formulate a scientific and feasible evaluation index system, and analyze it using entropy weight method and gray ideal correlation. The index system should combine operability while ensuring scientific comprehensiveness; in terms of evaluation results, it should ensure that it can reflect the essential characteristics of the object being evaluated; in terms of evaluation data, the source should be true and reliable. In general, the following principles should be adhered to the following:

(1) Accuracy. The definition of evaluation indicators is accurate, and the data sources are dependable and accurate. And there is no cross-overlap between indicators, and there is a major omission to avoid cross-overlap. Only by ensuring the accuracy of the indicator itself and the accuracy of the data source can be the requirements of accuracy be truly met.

(2) Reliability. When establishing a central indicator system for energy service city distribution sites, the source of reference materials should be reliable, the information should be true, and no fraud should be used. Only in this way can we ensure the objective, fair evaluation and provide a reliable basis for the 
next management work. The indicators can truly reflect the statistical content of the construction of the energy service city distribution site center and objectively reflect the true status of the project construction and the subsequent benefits.

(3) Combination of Representativeness and Difference. The selection of indicators can well reflect the influencing factors that need to be considered in the location of energy service city distribution sites. The indicators should reflect distinctive characteristics, highlight the differences between them, and have a comparison.

(4) Combination of Science and Practicality. The design index system should first follow the scientific basis and basic theories and conform to the objective laws. But on this basis, the characteristics of the actual project construction, the difficulty of data collection, and the difficulty of statistics should be considered. If the indicators are scientific but cannot be implemented in specific work, such indicators are meaningless.

(5) Combination of Quality and Quantity. Some of the actual problems can be evaluated by collecting specific data and calculation, but some problems cannot be measured quantitively. These problems cannot be ignored, and problems that cannot be evaluated through specific calculations should be evaluated qualitatively. The commonly used method is the Delphi method.

(6) Combination of Comprehensiveness and Importance. The index system should reflect the problem comprehensively and evaluate the location of the underground logistics node center according to certain logical design indicators from different angles. At the same time, too many indicators will increase the workload and cause unnecessary trouble. Therefore, the solution is to combine representativeness and importance, and unnecessary indicators can be properly ignored to reduce the cost of the evaluation work, and it can better highlight the characteristics of the object being evaluated.

The source service city distribution system is a new type of logistics concept system. In the process of site selection of the source service city distribution system network nodes, many factors need to be considered. In the establishment of the evaluation system of the source service city distribution system node, various indicators should be set for the characteristics of the source service city distribution site. In this paper, through careful review and analysis of relevant literature, reference to previous research results, combined with the characteristics of the source service city distribution site, it is concluded that the main consideration factors for the source service city distribution site location include item transmission [26]. The four factors of environment, technology, economy, and society are the main factors that must be considered when selecting the location of the source service city distribution site center, and these factors are converted into indicator structures, as shown in Figure 1.
2.2. Deep Learning Layout Model Construction. Comprehensive evaluation is carried out on multiple indicators of the evaluation sample. The problem to be solved by a comprehensive evaluation is to make an overall evaluation or ranking of each index value. The basic idea of the ideal solution is to determine the optimal sample point, the worst sample point, etc., as the reference point and then calculate the distance from each sample point to the reference point: the closer to the optimal sample point, the better, the farther from the worst sample point, the better.

Assuming that the weight of the indicators has been determined to be $w_{1}, w_{2}, \ldots, w_{n}$, the diagonal matrix $W$ is constructed with these as the main diagonal elements, namely,

$$
\Delta W=\left(\begin{array}{ccc}
w_{1} & \ldots & 0 \\
\ldots & w_{2} & \ldots \\
0 & \ldots & w_{n}
\end{array}\right)_{n^{*} n} .
$$

Based on the qualitative analysis of the researched transaction, the independent and dependent variables of the transaction are determined. The number of dependent variables is 1 , and there can be many independent variables. Let the dependent variable data constitute the reference sequence $L_{0}$, and the respective variable data constitute the comparison sequence $L_{\mathrm{i}}(i=1,2, \ldots, n)$, and $n+1$ data sequences from the following matrix:

$$
\begin{aligned}
(L 0, L 1, \ldots, L n) & =\left[\begin{array}{ccc}
l_{0}(1) & \ldots & l_{n}(1) \\
\ldots & \ldots & \ldots \\
l_{n}(N) & \ldots & l_{n}(N)
\end{array}\right]_{N^{*}(n+1)}, \\
L_{i} & =\left(l_{i}(1), l_{i}(2), \ldots, l_{i}(N)\right)^{T}, \quad i=0,1,2 \ldots n .
\end{aligned}
$$

Calculate the absolute difference between the reference sequence and the remaining comparison sequences during the corresponding period to form the following absolute difference matrix:

$$
\begin{aligned}
\operatorname{Adm} & =\left[\begin{array}{ccc}
a_{0}(1) & \ldots & a_{n}(1) \\
\ldots & \ldots & \ldots \\
a_{n}(N) & \ldots & a_{n}(N)
\end{array}\right]_{N^{*} n}, \\
a_{i}(k) & =\left|l_{0}(k)-l_{i}(k)\right|, \quad i=0,1,2, \ldots, n ; k=0,1,2, \ldots, N .
\end{aligned}
$$

Genetic algorithm is used to optimize a complex model, the complex model can be built by Simulink, including all the constraints are built in Simulink, and then the model is imported into the genetic algorithm program. The more difficult part of this part is the establishment of Simulink, especially when there are many coupled models. According to the location selection scheme, the fitness of the two objective functions is obtained, respectively. The model knows that the key to solving $G_{1}$ and $G_{2}$ is to calculate the goods from the distribution point of the goods to the energy service city distribution site. The distribution volume $\mathrm{L}_{\mathrm{ik}}$ and the volume of goods are delivered to the demand center by the node center 


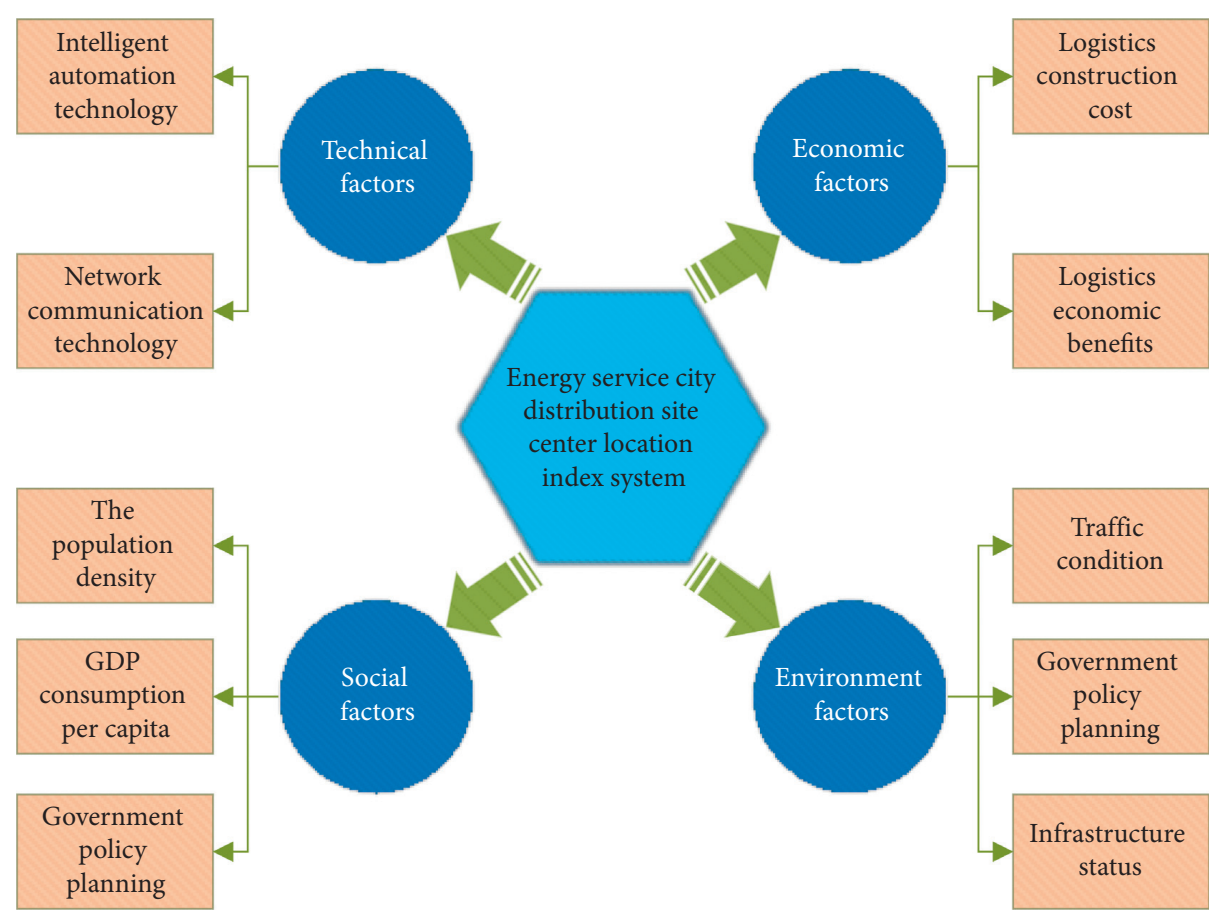

FIGURE 1: Energy service city distribution site center location index structure diagram.

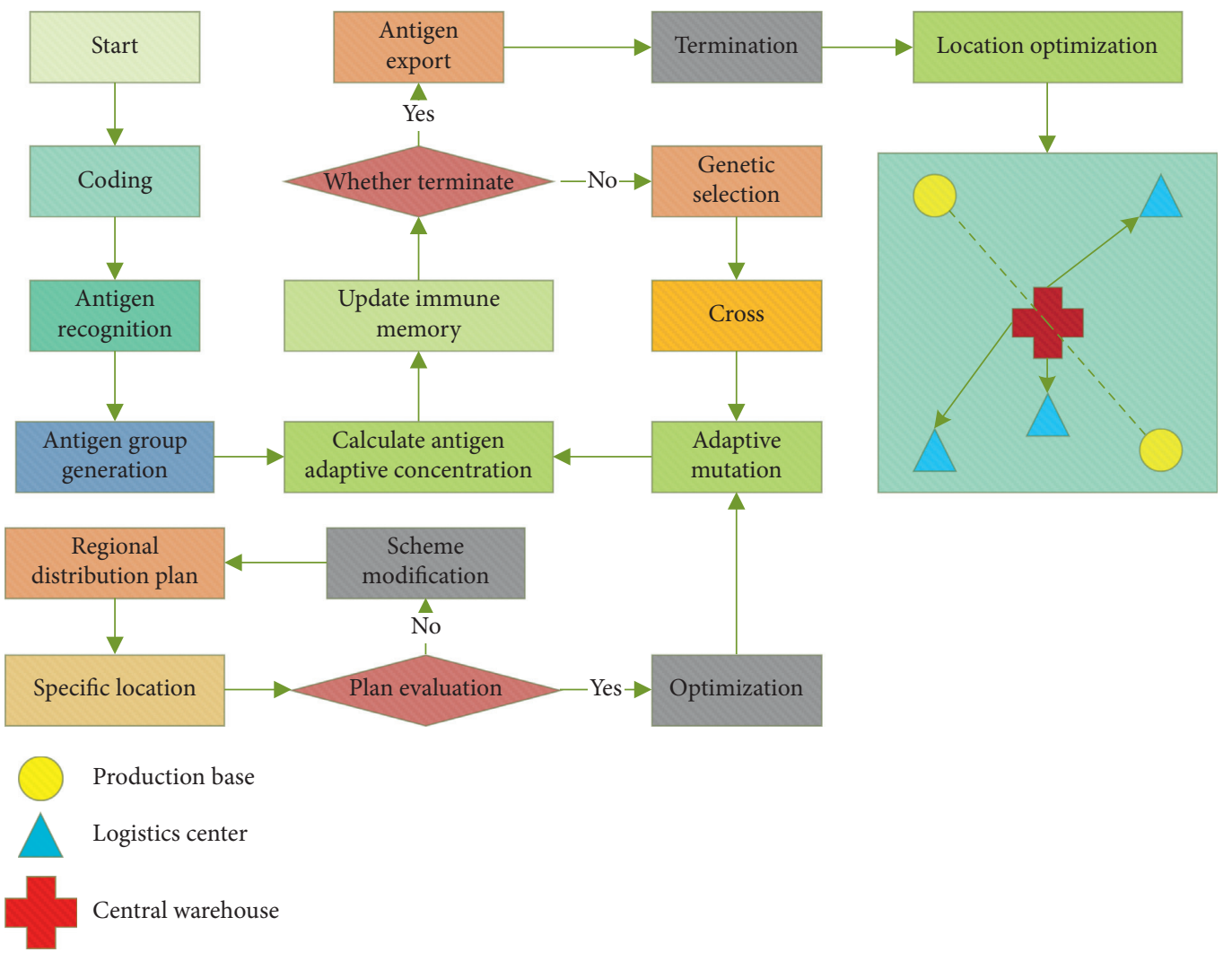

FIGURE 2: Genetic algorithm layout. 
$\mathrm{L}_{\mathrm{kj}}$. Using genetic algorithm, the specific layout scheme is shown in Figure 2.

The expert group evaluated 10 candidate addresses and summarized the results, as shown in Table 1.
The entropy weight of each evaluation index is obtained, and the results of the standardized weighted evaluation matrix are shown in Table 2.

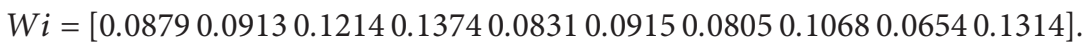

2.3. Path Optimization Model Constructions. In order to make integrated decisions on the location selection of the distribution center facilities and vehicle routing of the energy service city distribution site network and to achieve the minimum total system cost for the third-party logistics companies in the energy service city common distribution operation, an LRP problem model was established. The objective function is the lowest total system cost for the location selection and vehicle routing of the energy service city distribution site center. The objective functions are shown in the formulas (5), (6), and (7). Formula (5) represents the total system cost of energy service city distribution site selection and vehicle routing, including three parts of costs-distribution center related costs, vehicle related costs, and customer time penalty costs; formula (6) indicates the construction of a common distribution center. The cost and the operating cost of goods in the distribution center are the lowest. Formula (7) represents the lowest acquisition cost and transportation cost of distribution vehicles, including the corresponding costs of cold chain vehicles and ordinary vehicles:

$$
\begin{aligned}
\min G & =\min G_{1}+\min G_{2}, \\
G_{1} & =\sum_{i=1}^{M} G M_{i}^{*} L_{i}+\sum_{i=1}^{M} \sum_{j=1}^{N} G N_{i}^{*}\left(u_{j}+e_{j}\right)^{*} Y_{i j} \\
G_{2} & =\sum_{k=1}^{M} G M_{k}\left(\sum_{i=1}^{M} \sum_{j=1}^{N} L_{i j k}\right)+\sum_{k=1}^{N} G N_{k}\left(\sum_{i=1}^{M} \sum_{j=1}^{N} L_{i j k}\right) .
\end{aligned}
$$

The main constraints of the model include distribution center capacity constraints, distribution vehicle capacity constraints, and time window constraints. The constraints model is as follows:

$$
\begin{aligned}
M_{j k} & =\sum_{j=1}^{N} L_{i j k}{ }^{*}\left(M_{i k}+t_{i k}+t_{i j k}\right), \\
\sum_{j=1}^{M} L_{i j k} & =\sum_{i=1}^{M} \sum_{j=1}^{N} u_{j}^{*} L_{i j k} .
\end{aligned}
$$

The maximum coverage model is similar to the cluster analysis for solving the location problem. The design is simple, the structure is clear, and it is easy to implement. In addition, the maximum coverage model considers the capacity constraints of the facility, which is more realistic. There are also two improvements:
First, seek the best strategy, like cluster analysis. The optimization strategy of the number of facility nodes is to iterate from more to less. When the scale of candidate facilities is large, it will affect the efficiency of optimization.

Second, the overall strategy, the maximum coverage model, is efficient in solving the single problem of facility location and the solution result is also very good. However, in the study of facility location-vehicle routing integrated planning problem, the connection between the two subproblems is ignored, which is easy. To get the overall suboptimal solution, the site selection stage of the facility needs to strengthen the consideration of the later route arrangement stage.

In the network structure composed of the largest coverage of facility nodes and customer nodes, vehicle routes of facility nodes are reasonably arranged, and iterative optimization is performed through a certain strategy to obtain the best transportation and distribution route arrangement. The optimal path optimization process is shown in Figure 3.

In the energy service city distribution network optimization model, the LRP problem can be divided into two subproblems, LAP and VRP, and the solution process must consider the interaction between the two subproblems, paying particular attention to the dynamic changes in distribution costs caused by different facility allocation results. In the site selection stage of the facility, the common distribution center that is close to the customer is given priority until the total customer demand exceeds the facility capacity and then adjusted according to the capacity of the energy service city distribution center; the number is the least. The construction center of the distribution center has high and concentrated investment, and the investment of multiple facilities will bring real problems such as financial pressure to the enterprise. Therefore, on the promise of satisfying the needs of customers, we strive to minimize the number of facilities.

The population size in the genetic algorithm represents the number of feasible solution sets, and it is also the scale of parallel optimization and exploration. If the population size is too small, it will affect the efficiency of optimization, and the optimization results are easy to fall into the local optimal; too large population size will improve the global optimality of the optimization results, but at the same time will lead to a sharp increase in the complexity of the algorithm and higher requirements for device hardware. Therefore, it is necessary to set the size of the population size according to the size of the solution scale. In this paper, the population size is set to 100 during design, which is in accordance with the conventional interval of 0 to 200. Finding out the constraints 
TABLE 1: Correspondence table of index evaluation values.

\begin{tabular}{lcccccccccc}
\hline Candidate address & C11 & C12 & C13 & C14 & C21 & C22 & C31 & C32 & C41 & C42 \\
\hline A1 & 9 & 8 & 6 & 7 & 9 & 7 & 5 & 7 & 4 & 9 \\
A2 & 5 & 5 & 6 & 5 & 4 & 4 & 8 & 4 & 6 \\
A3 & 8 & 7 & 6 & 8 & 7 & 4 & 5 & 4 & 6 \\
A4 & 5 & 8 & 8 & 3 & 4 & 6 & 7 & 6 & 4 \\
A5 & 7 & 10 & 5 & 5 & 4 & 6 & 8 & 8 & 7 \\
A6 & 8 & 8 & 7 & 5 & 6 & 8 & 10 & 3 & 5 \\
A7 & 10 & 5 & 8 & 7 & 6 & 3 & 6 & 5 & 7 \\
A8 & 7 & 7 & 10 & 5 & 8 & 5 & 6 & 5 & 8 \\
A9 & 8 & 8 & 9 & 7 & 8 & 5 & 4 & 7 & 8 \\
A10 & 7 & 10 & 7 & 8 & 9 & 7 & 4 & 5 & 5 \\
\hline
\end{tabular}

TABle 2: Normalized weighted evaluation matrix result table.

\begin{tabular}{lcccccccccc}
\hline Candidate address & C11 & C12 & C13 & C14 & C21 & C22 & C31 & C32 & C41 & C42 \\
\hline A1 & 0.0121 & 0.0107 & 0.0067 & 0.0107 & 0.0067 & 0.0080 & 0.0094 & 0.0067 & 0.0107 & 0.0107 \\
A2 & 0.0067 & 0.0067 & 0.0107 & 0.0067 & 0.0080 & 0.0094 & 0.0107 & 0.0080 & 0.0134 & 0.0067 \\
A3 & 0.0107 & 0.0080 & 0.0067 & 0.0080 & 0.0094 & 0.0107 & 0.0134 & 0.0094 & 0.0094 & 0.0080 \\
A4 & 0.0067 & 0.0094 & 0.0080 & 0.0094 & 0.0107 & 0.0134 & 0.0094 & 0.0107 & 0.0107 & 0.0094 \\
A5 & 0.0080 & 0.0107 & 0.0094 & 0.0107 & 0.0134 & 0.0094 & 0.0107 & 0.0134 & 0.0107 & 0.0107 \\
A6 & 0.0094 & 0.0134 & 0.0107 & 0.0134 & 0.0094 & 0.0107 & 0.0107 & 0.0067 & 0.0080 & 0.0107 \\
A7 & 0.0107 & 0.0094 & 0.0134 & 0.0107 & 0.0107 & 0.0107 & 0.0080 & 0.0107 & 0.0107 & 0.0067 \\
A8 & 0.0134 & 0.0107 & 0.0067 & 0.0067 & 0.0067 & 0.0080 & 0.0094 & 0.0067 & 0.0134 & 0.0080 \\
A9 & 0.0094 & 0.0107 & 0.0107 & 0.0080 & 0.0080 & 0.0094 & 0.0094 & 0.0067 & 0.0094 & 0.0094 \\
A10 & 0.0107 & 0.0134 & 0.0067 & 0.0067 & 0.0094 & 0.0107 & 0.0107 & 0.0080 & 0.0107 & 0.0107 \\
\hline
\end{tabular}

and objective function is the key. It is necessary to analyze the topic carefully and clarify the clues. When the amount is large, you can list it into a table, find all the constraints, list the inequality groups, and then combine the graphics to find the optimal solution.

Evolutionary algebra is used as the termination parameter of the algorithm's optimization calculation. The genetic algorithm will stop the optimization when it reaches the specified evolutionary algebra and at the same time output the current best optimization result. Evolutionary algebra is set according to the scale of the solution. The scale of the problem solved in this paper is not large. Setting the evolutionary algebra to 300 generations is completely sufficient to obtain the global optimal solution.

\section{Results Analysis}

3.1. Model Analyses. In the alternative energy service city distribution site (A1-A10), at least one energy service city distribution site center is selected. The goal is to establish a logistics node so that the node construction cost is the lowest and the customer service is optimal. The simulation analysis results are shown in Figure 4.

After iteration, the calculation results of the decision variables are $\mathrm{z} 1, \mathrm{z3}, \mathrm{z} 7, \mathrm{z} 9, \mathrm{z} 10=1 ; \mathrm{z} 8=0$, so the underground logistics transit nodes to be built are A1, A3, A7, A9, and A10, and the total cost is 12.3100 million yuan, the maximum covered cargo transportation volume within the optimal radius is 698 tons, and the coverage rate reaches more than $98 \%$. The location planning scheme based on immune genetic algorithm is shown in Figure 5. The number of distribution demands sites and distribution objects of each node center. Node center A1 is responsible for delivering goods to demand sites $\mathrm{C} 1, \mathrm{C} 8$, and $\mathrm{C} 11$, node center $\mathrm{A} 3$ is responsible for delivering goods to demand sites $\mathrm{C} 2$ and $\mathrm{C} 10$, and node center $\mathrm{A} 10$ is responsible for delivering goods to material demand points $\mathrm{C} 3, \mathrm{C} 4, \mathrm{C} 6$, and $\mathrm{C} 14$.

3.2. Layout Analyses. Figure 6 shows the changes in the strategy selection of supervision punishment with different intensities, where curves $1,2,3$, and 4 in the figure represent the energy service distribution when implementing the "supervision punishment" mechanism, and the penalty $Z$ is $0.6,1.2$. In the case of 1.8 and 2.2 , the strategic choice of logistics enterprise group decisionmaking behavior changes. It can be seen from curve 1 in the figure that when the degree of "supervision and punishment" mechanism is weak, the enthusiasm of the logistics enterprise group for cooperative business is not strong, and its willingness to cooperate is also slightly lower. However, with the increase of the "supervision and punishment" mechanism, the willingness of the logistics enterprise group to cooperate will gradually increase, and the cooperation between the enterprise groups of the two parties will gradually evolve toward continuing the energy service distribution strategy, but this evolution strategy has no persistence, because enterprises subjectively have certain constraints on supervision and punishment constraints. Therefore, after a certain period of time, their strategic behavior will evolve toward the direction of energy service distribution breakdown, as showed in curve 2. However, it can be seen from the change of curve 3 in the figure that when the "supervision penalty" mechanism 


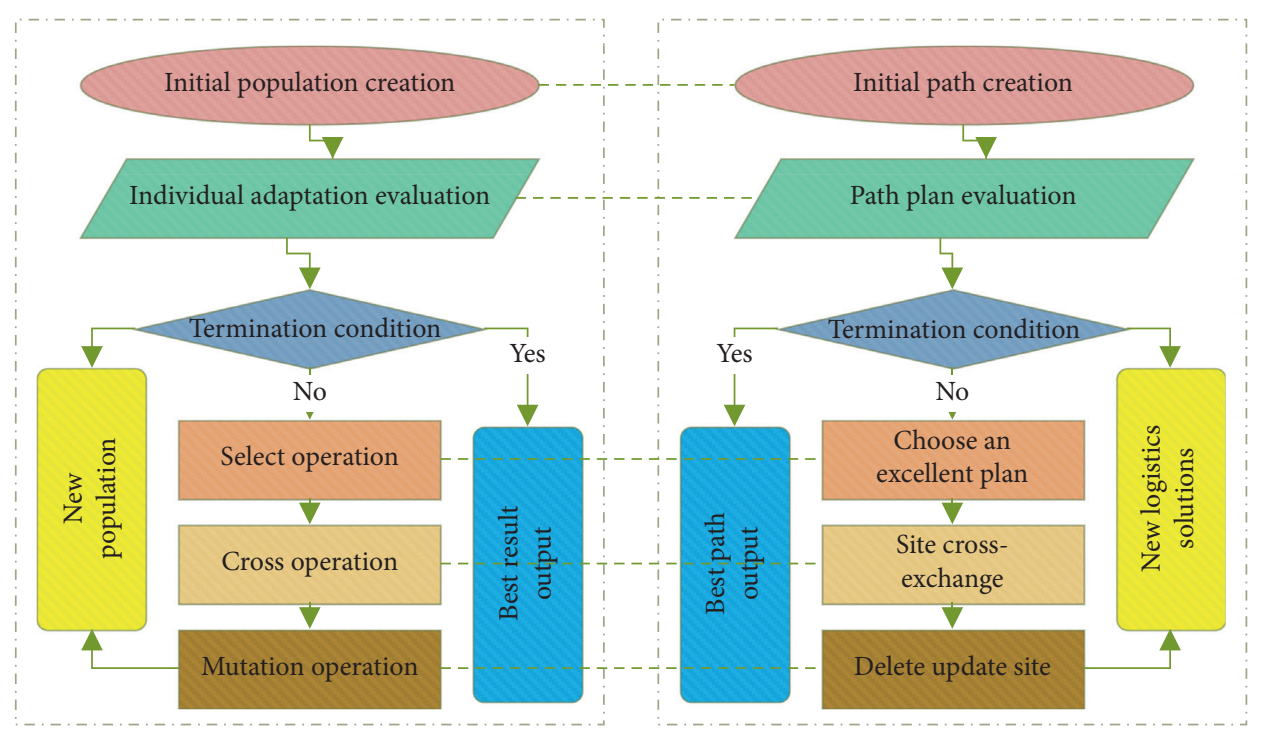

Figure 3: Optimal path optimization.

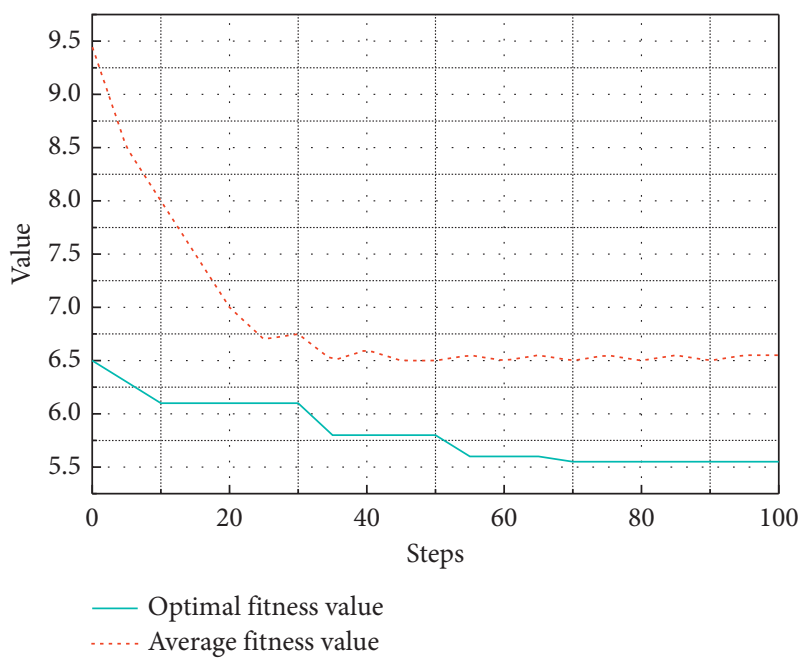

FIgURE 4: Model convergence curve.

of energy service distribution is more serious, that is, the fine is further increased, the logistics enterprise group will choose to continue the strategy of energy service distribution due to the larger default cost. Energy service distribution will eventually reach dynamic stability. However, when the file exceeds a certain level, it will cause a rebound in the decision-making of the logistics enterprise group, so that it will initially transform its decisionmaking behavior into an energy service distribution split due to this reason. Figure 7 is a simulation of the changes in the expected returns of different levels of supervision and punishment. From the changes in the corresponding curves in Figure 7, it can also be seen that the probable changes of logistics enterprise groups when they continue to make energy service distribution decisions are the same as their expected returns.

In view of the uncontrollable external potential risks such as environmental risks in the operation of the

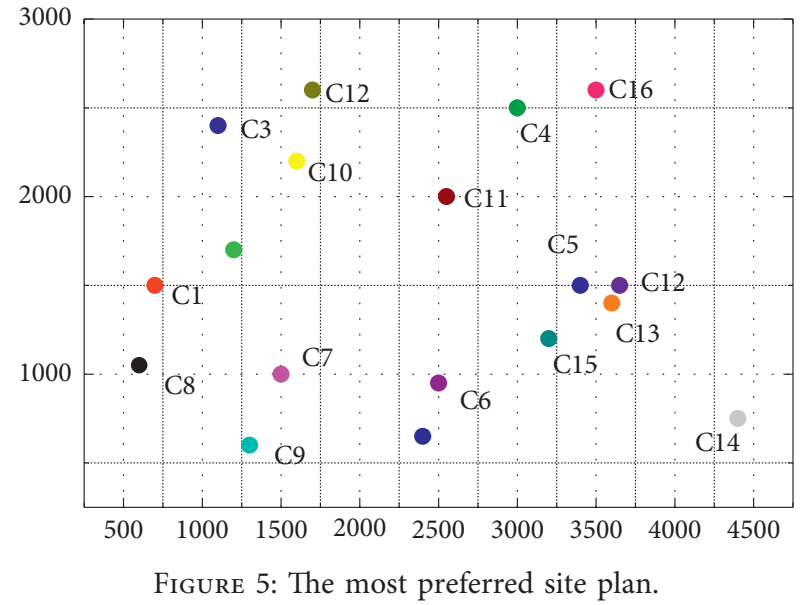

e-commerce logistics alliance, the alliance can build a platform for the communication and operation of the e-commerce logistics alliance by using cloud platforms or other new technologies to create a long-term communication mechanism to promote internal differences. Enterprises belonging to different regions can effectively share information, so that different member companies can prevent business external and internal environmental risks in a timely manner, such as natural environmental disasters in logistics and transportation, international situation and policy changes, external environmental risks, and internal members. The losses and injuries caused by the internal and external environmental risks such as organization management and operation to the energy service distribution operation. At the same time, enterprises also need to formulate the corresponding operating environment risk avoidance strategies in order to reduce the losses caused by environmental risks as much as possible.

On the premise of using the deep learning algorithm to analyze the risk of energy service distribution operation, the 


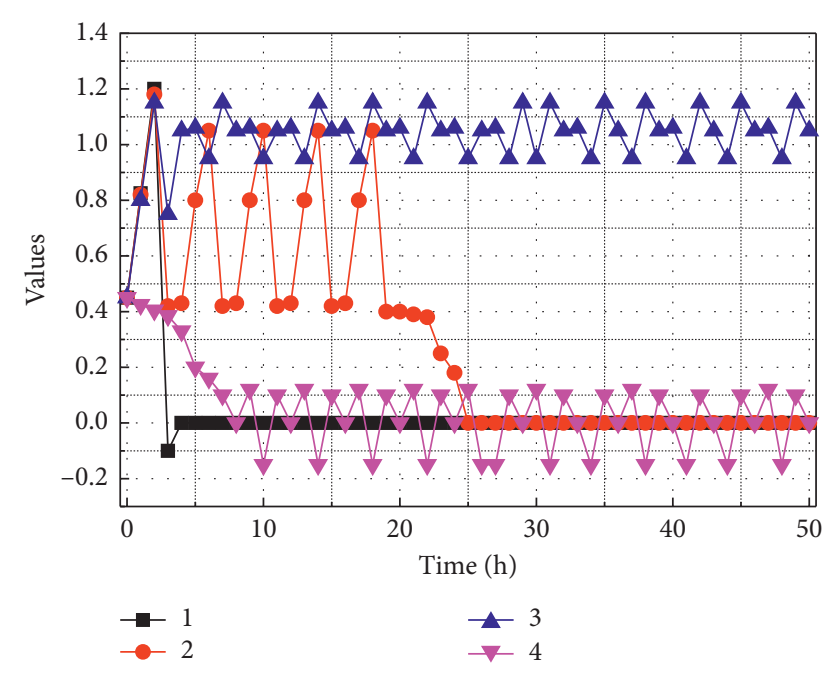

Figure 6: Selection changes under different intensity penalty strategies.

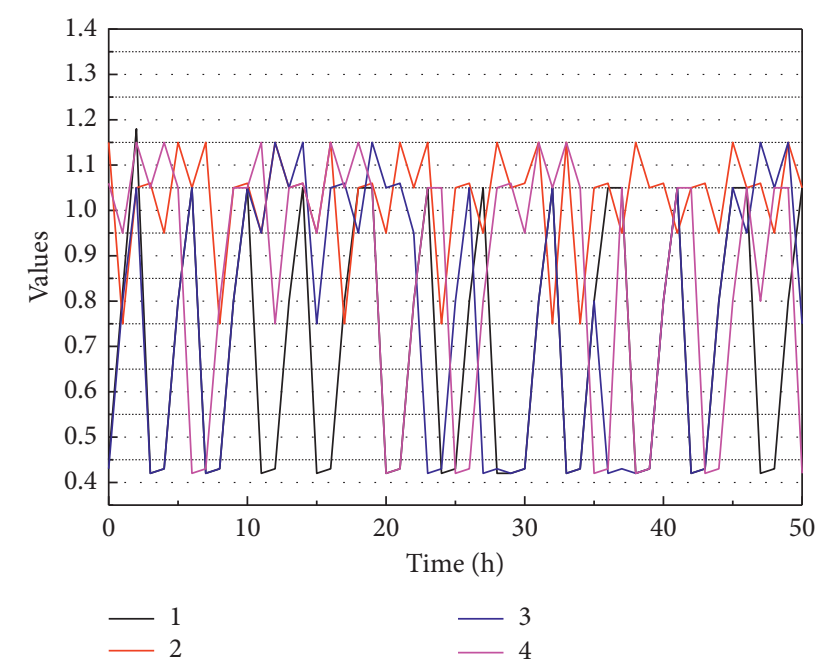

FIgURE 7: Changes in the expected returns of penalties under different levels of supervision.

establishment of a deep learning-based energy service distribution e-commerce logistics alliance operation risk evolution game model, and further discussion of energy service distribution e-commerce logistics alliance operation risk control issues, it is found that operating the system dynamics game can effectively characterize the evolutionary game of energy service distribution operation risk and reveals that, under different operational risk states, the logistics enterprise groups existing in energy service distribution under different "operational risk" states, enterprises. The changes in strategic choices also indicate the effectiveness of deep learning methods in studying the operational risk of energy service distribution e-commerce logistics alliances. By characterizing enterprises in different operational risk states, they also provide energy service distribution e-commerce logistics alliances, reducing operational risks, maintaining stable operation of energy service distribution, and putting forward relevant suggestions.
3.3. Path Optimization Analyses. For $\mathrm{S} 2+\mathrm{S} 5$ and $\mathrm{S} 1+\mathrm{S} 5$, based on the subdivision clusters determined for each plan in the distribution center location stage, according to the demand characteristics of each distribution center cold chain and ordinary customers, each subdivision cluster is routed in sequence, and finally the optimal routing decision of the distribution center location plan is obtained. The delivery time requires all customers to complete the delivery task within an hour. First, the customer group of the distribution center in the location selection plan 1 (S2 + S5) is used to arrange vehicle routes, and the genetic algorithm program is designed to iteratively calculate. The basic parameter settings of the algorithm include the following: the number of iteration terminations is 300 , the population size is 100 , the crossover probability is 0.9 , and the mutation probability is 0.1 . The setting of larger crossover probability and mutation probability is to ensure the diversity of the population and improve the accuracy of the algorithm. When using a genetic algorithm to solve the LRP of the energy service city common distribution network, the algorithm shows good convergence, and all of them can reach the lowest system cost before the 50th generation. The process of population evolution is shown in Figure 8. It is calculated that the S2 distribution center cold chain customer route requires 4 vehicles, and the system cost is 16191.753 yuan; the ordinary customer line requires 5 vehicles, and the system cost is 1560.894 yuan; the S5 distribution center cold chain customer route requires 6 vehicles, and the system cost is 2890.587 yuan; the ordinary customer route requires 3 vehicles, and the system cost is 923.1052 yuan.

Through the iterative optimization of facility location and vehicle routing in the first two stages, two distribution centers and routing arrangements are obtained. The first is the S2 and S5 distribution centers and the corresponding routing. The total cost of the first one is 6,994 yuan. The second plan is the S1 and S5 distribution centers and the corresponding route arrangements. The total cost of the second plan is 7363 yuan. Therefore, in the energy service city distribution logistics network in this example, S2 and S5 should be selected as the energy service city distribution common distribution center, and the corresponding vehicle distribution route should be arranged. Considering the site selection cost and distribution cost of different site selection schemes comprehensively, the site selection scheme with the lowest comprehensive cost is selected and the best vehicle route arrangement is obtained.

In actual decision-making, different time windows and different delivery and delivery strategies will then make the decision process more complicated. The constraint set in the example is the service mode of completing the delivery time window and taking delivery at the same time within one hour. In the sensitivity analysis, the impact of different time windows and different delivery and delivery strategies will be discussed, and corresponding optimization suggestions will be put forward. Figure 9 shows the changes in the number of distribution vehicles and the total cost of the system under different time requirements. Vehicle distribution costs and time punishment costs will produce a contradiction of 


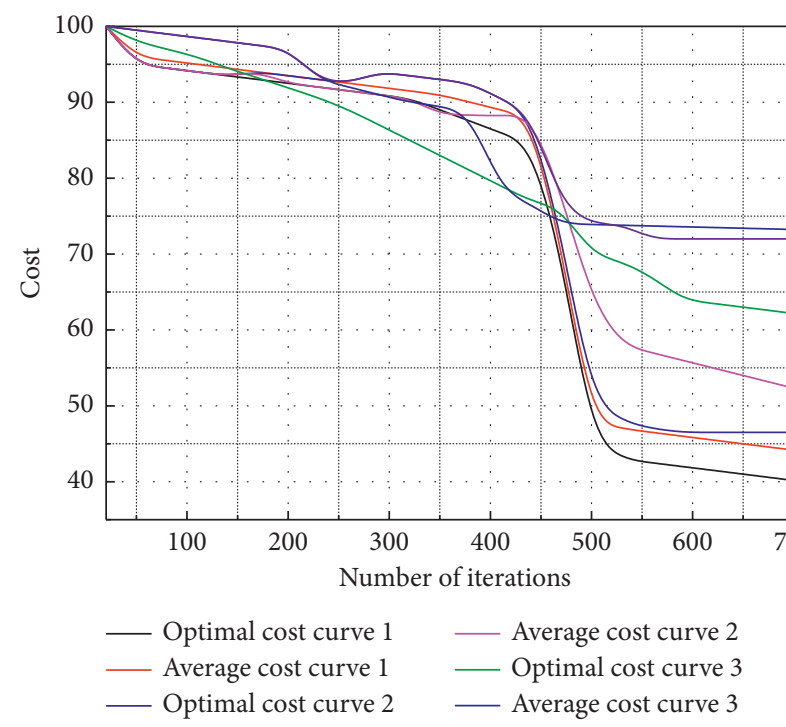

Figure 8: Distribution process of distribution center routing.

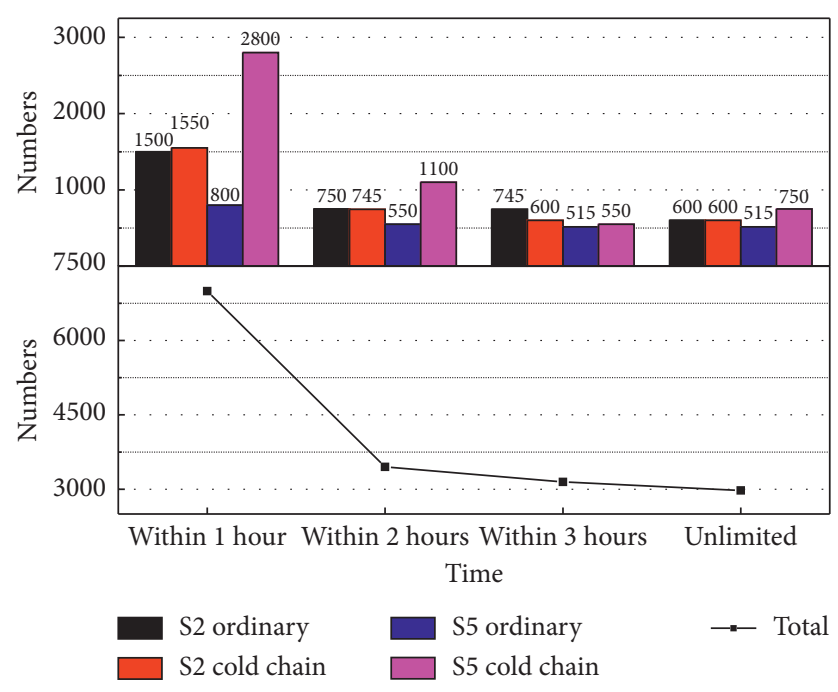

Figure 9: Changes in total system cost under the same time window.

benefits. If the number of vehicles to be distributed is small and more customers are served by one vehicle, the cost of vehicle purchase and distribution will be reduced, but the cost of customer time penalty will be increased; if the vehicles are added for distribution, this will reduce the cost of customer's time penalty, but will increase the cost of vehicle use and distribution costs.

The processing strategy for two-way logistics needs is to pick and deliver goods at the same customer service at the same time, adjust the delivery and delivery strategy, adopt the strategy of first delivery and then delivery, and compare with the simultaneous delivery and delivery strategy. Expanding the research to compare the two deliveries and delivery strategies between cold chain customers and ordinary customers without time constraints, and after modifying the fitness function of the genetic algorithm in MATLAB and simulating, the two types of routing arrangements are shown in Figure 10. In the simultaneous delivery mode, the total system cost is 2970 yuan; in the first delivery mode, the total system cost is 3250 yuan. At the same time, the system cost of the pickup-and-delivery model is $8.6 \%$ lower than that of the first-and-after-delivery model, but the premise of the simultaneous pick-and-delivery is that after the delivery service is provided to current customers, the vehicle's remaining capacity is sufficient to meet the demand for pickup. Therefore, the main distribution business entity of the energy service city should adopt the service mode of taking delivery at the same time when the capacity of the vehicle permits when making arrangements for taking delivery business. 

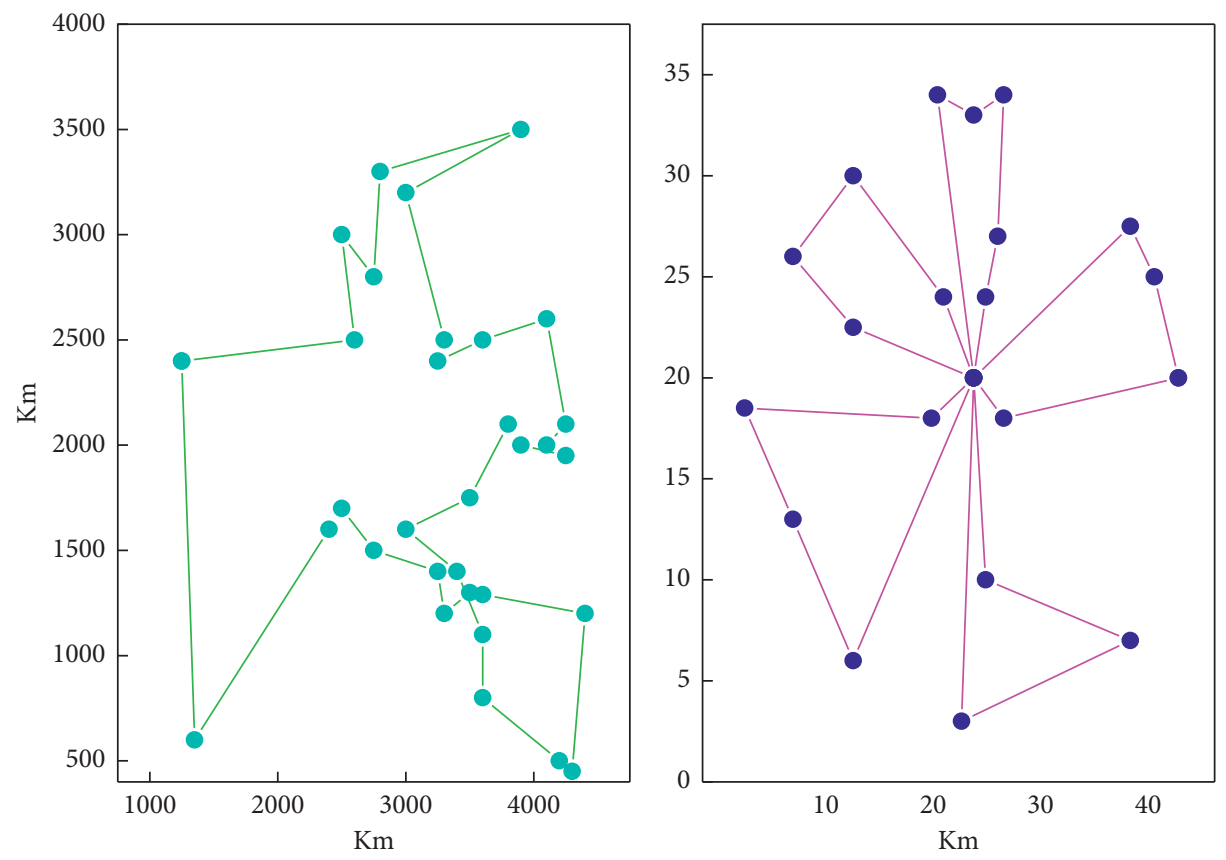

FigURE 10: Route arrangement under different delivery and delivery strategies.

\section{Conclusion}

In this paper, the common distribution network and operation of energy service cities based on two-way logistics are different from logistics service networks that only focus on the energy logistics market or focus on the urban logistics market. They are more complicated in terms of service demand and customer characteristics and fully consider energy service cities. In the logistics market, cold chain customers and ordinary customers have different characteristics such as time requirements and demand. Reasonably design an example of the energy service city common distribution center and its vehicle routing problem under realistic constraints, solve the location and routing decision of the distribution center through the designed model and algorithm, and based on different time windows and delivery strategies perform sensitivity analysis. The calculation example validates the validity and versatility of the model algorithm and at the same time provides a theoretical reference for the decision-making of codistribution operators in energy service cities. This article is based on the research of existing facility location-vehicle routing issues, based on the unique organizational structure and operation method of the energy service city common distribution network, and comprehensively considers the time window requirements, pickup needs, and delivery of different customer groups. Different logistics service constraints such as demand, in the modeling and solving process, consider the connection between the two subproblems of facility location and vehicle routing and realize the integration and optimization of the two-way common distribution network of the energy service city in order to integrate the energy service city logistics. The construction and operation of energy service city logistics network provides theoretical guidance and practical support. The LRP optimization model of the energy service city common distribution network constructed in this paper belongs to the multifacility, multimodel, capacity limited, time-constrained, and two-way circulation facility locationvehicle routing problem model that takes delivery at the same time, considering the realistic factors more comprehensive and more practical guidance.

\section{Data Availability}

The data used to support the findings of this study are available from the corresponding author upon request.

\section{Conflicts of Interest}

The authors declare that they have no conflicts of interest.

\section{References}

[1] Z. Chen, J. Dong, and R. Ren, "Urban underground logistics system in China: opportunities or challenges?" Underground Space, vol. 2, no. 3, pp. 195-208, 2017.

[2] M. Savelsbergh and T. Van Woensel, "50th anniversary invited article-city logistics: challenges and opportunities," Transportation Science, vol. 50, no. 2, pp. 579-590, 2016.

[3] J. Sachs, L. A. A. Andersson, J. Araujo et al., "Adaptive 5G low-latency communication for Tactile Internet services," Proceedings of the IEEE, vol. 107, no. 2, pp. 325-349, 2018.

[4] C. Willing, T. Brandt, and D. Neumann, "Electronic mobility market platforms - a review of the current state and applications of business analytics," Electronic Markets, vol. 27, no. 3, pp. 267-282, 2017.

[5] E. Paffumi, M. De Gennaro, and G. Martini, "European-wide study on big data for supporting road transport policy," Case Studies on Transport Policy, vol. 6, no. 4, pp. 785-802, 2018. 
[6] X. Chen, H. H. Wang, and B. Tian, "Visualization model of big data based on self-organizing feature map neural network and graphic theory for smart cities[J," ]. Cluster Computing, vol. 22, no. 6, pp. 13293-13305, 2019.

[7] J. Zhang, J. Fan, and H. Shen, "A study of the development framework of the travel application of public information service for urban tourism[J]," Tourism, Leisure and Global Change, vol. 1, no. 1, pp. 161-182, 2016.

[8] P. V. Klaine, M. A. Imran, O. Onireti, and R. D. Souza, "A survey of machine learning techniques applied to self-organizing cellular networks," IEEE Communications Surveys and Tutorials, vol. 19, no. 4, pp. 2392-2431, 2017.

[9] A. T. C. Onstein, M. Ektesaby, J. Rezaei, L. A. Tavasszy, and D. A. van Damme, "Importance of factors driving firms' decisions on spatial distribution structures," International Journal of Logistics Research and Applications, vol. 23, no. 1, pp. 24-43, 2020.

[10] M. Krivy, "Towards a critique of cybernetic urbanism: the smart city and the society of control," Planning Theory, vol. 17, no. 1, pp. 8-30, 2018.

[11] A. Wiig, "The empty rhetoric of the smart city: from digital inclusion to economic promotion in Philadelphia," Urban Geography, vol. 37, no. 4, pp. 535-553, 2016.

[12] R. Raven, F. Sengers, P. Spaeth, L. Xie, A. Cheshmehzangi, and M. de Jong, "Urban experimentation and institutional arrangements," European Planning Studies, vol. 27, no. 2, pp. 258-281, 2019.

[13] H. Verrest and K. Pfeffer, "Elaborating the urbanism in smart urbanism: distilling relevant dimensions for a comprehensive analysis of Smart City approaches," Information, Communication \& Society, vol. 22, no. 9, pp. 1328-1342, 2019.

[14] I. A. T. Hashem, V. Chang, N. B. Anuar et al., "The role of big data in smart city," International Journal of Information Management, vol. 36, no. 5, pp. 748-758, 2016.

[15] S. Barns, E. Cosgrave, M. Acuto, and D. Mcneill, "Digital infrastructures and urban governance," Urban Policy and Research, vol. 35, no. 1, pp. 20-31, 2017.

[16] D. Gagliardi, L. Schina, M. L. Sarcinella, G. Mangialardi, F. Niglia, and A. Corallo, "Information and communication technologies and public participation: interactive maps and value added for citizens," Government Information Quarterly, vol. 34, no. 1, pp. 153-166, 2017.

[17] D. Eckhoff and I. Wagner, "Privacy in the smart cit$\mathrm{y}$-applications, technologies, challenges, and solutions," IEEE Communications Surveys and Tutorials, vol. 20, no. 1, pp. 489-516, 2017.

[18] F. D. Sandulli, A. Ferraris, and S. Bresciani, "How to select the right public partner in smart city projects," R\&D Management, vol. 47, no. 4, pp. 607-619, 2017.

[19] U. Rossi, "The variegated economics and the potential politics of the smart city," Territory, Politics, Governance, vol. 4, no. 3, pp. 337-353, 2016.

[20] N. Kumar, A. V. Vasilakos, and J. J. P. C. Rodrigues, "A multitenant cloud-based DC nano grid for self-sustained smart buildings in smart cities," IEEE Communications Magazine, vol. 55, no. 3, pp. 14-21, 2017.

[21] M. Sookhak, H. Tang, Y. He et al., "Security and privacy of smart cities: a survey, research issues and challenges," IEEE Communications Surveys and Tutorials, vol. 21, no. 2, pp. 1718-1743, 2018.

[22] R. Kitchin, "The realtimeness of smart cities," TECNOSCIENZA: Italian Journal of Science and Technology Studies, vol. 8, no. 2, pp. 19-42, 2018.
[23] J. Wang, C. Jiang, K. Zhang et al., "Vehicular sensing networks in a smart city: principles, technologies and applications," IEEE Wireless Communications, vol. 25, no. 1, pp. 122-132, 2017.

[24] K. Vu and K. Hartley, "Promoting smart cities in developing countries: policy insights from Vietnam," Telecommunications Policy, vol. 42, no. 10, pp. 845-859, 2018.

[25] G. V. Pereira, M. A. Macadar, E. M. Luciano, and M. G. Testa, "Delivering public value through open government data initiatives in a Smart City context," Information Systems Frontiers, vol. 19, no. 2, pp. 213-229, 2017.

[26] C. Gaffney and C. Robertson, "Smarter than smart: rio de Janeiro's flawed emergence as a smart city," Journal of Urban Technology, vol. 25, no. 3, pp. 47-64, 2018. 